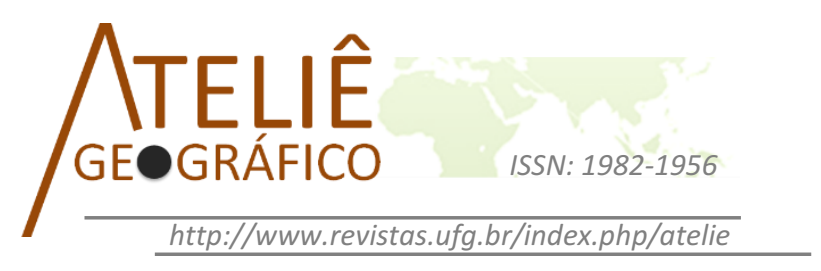

\title{
A mobilidade pendular na Região Metropolita de Goiânia em 2010
}

\author{
The commuting in the Metropolitan Region of Goiânia in \\ 2010
}

\section{La Movilidad Pendular En La Región Metropolitana De Goiânia En 2010}

\author{
Larissa Camilo Nunes \\ Universidade Federal de Goiás \\ larissacamilonunes@gmail.com
}

\begin{abstract}
Resumo
No contexto da Região Metropolitana de Goiânia (RMG), a capital do estado se constitui como centro polarizador e detêm as melhores condições infraestruturais. Em função disso, os indivíduos se deslocam diariamente a esse pólo em busca de postos de trabalho, oportunidades educacionais, serviços de saúde, lazer, etc. Nesse sentido, esta pesquisa objetiva compreender o processo de mobilidade pendular no ano de 2010 na RMG a partir da relação entre deslocamentos e dinâmica socioeconômica. Os procedimentos metodológicos basearam-se em leitura bibliográfica e o levantamento de dados em fonte secundária. Ao mesmo tempo em que a mobilidade possibilita a integração de diversas localidades, ela também imobiliza, criando uma segregação social da sociedade urbana. Os indivíduos que gozam de poucas condições financeiras, nesse sentido, são os mais afetados por residirem em regiões mais distantes bem como pelas condições do transporte ofertado.
\end{abstract}

Palavras-chave: Mobilidade pendular, Região Metropolitana de Goiânia, Dinâmica espacial.

\begin{abstract}
In the context of Metropolitan Region of Goiania (MRG), the state capital is constituted as polarizing center and retains the best infrastructural conditions. As a result, individuals move daily to this pole in search of jobs, educational opportunities, health services, entertainment, etc. This research, therefore, aims to understand the commuting process in 2010 in MRG from the relationship between displacements and socio-economic dynamics. The methodological procedures are based on a literature review and data collection in secondary source. At the same time that the mobility enables the integration of different locations, it also immobilize, creating a social segregation of urban society. People, who have poor
\end{abstract}


financial conditions, in this sense, are the most affected because they live in more distant regions as well as for the offered transportation conditions.

Keywords: Commuting, Metropolitan Region of Goiânia, Spatial Dynamics.

Resumen: En el contexto de la Región Metropolitana de Goiânia (RMG), la capital del estado se constituye como centro polarizador y mantiene las mejores condiciones de infraestructura. De este modo, los individuos se mueven diariamente para este polo en busca de trabajo, oportunidades de educación, servicios de salud, ocio, etc. En este sentido, la presente investigación tiene como objetivo comprender el proceso de movilidad pendular en 2010 en la RMG a partir de la relación entre desplazamientos y la dinámica socioeconómica. Los procedimientos metodológicos se basaron en lectura bibliográfica y levantamiento de datos en fuente secundaria. Al mismo tiempo que la movilidad posibilita la integración de diversas localidades, ella también inmoviliza, creando una segregación social de la sociedad urbana. Los individuos que disfrutan de pocas condiciones financieras, en ese sentido, son los más afectados por residir en regiones más distantes así como por las condiciones del transporte ofertado.

Palabras clave: Movilidad Pendular; Región Metropolitana de Goiânia; Dinámica Espacial.

\section{Introdução}

A mobilidade espacial é um importante instrumento para compreendermos o processo de urbanização das cidades e suas dinâmicas socioespaciais. Nesse aspecto, a centralidade e os deslocamentos intra-metropolitanos ganham destaque nos estudos sobre mobilidade em função da sua relevância social, política e econômica. A necessidade desses deslocamentos acaba evidenciando a importância, no ambiente metropolitano, do acesso aos espaços que oferecem educação, saúde, trabalho, entre outros.

Nesse sentido, a mobilidade pendular assume papel de destaque nas regiões metropolitanas brasileiras por evidenciar as desigualdades socioespaciais existentes nos municípios que integram essas regiões e, também, a centralidade de uma área de atração e dispersão de fluxos de pessoas, mercadorias, informações etc. Percebe-se que em boa parte dos municípios metropolitanos periféricos os recursos econômicos públicos não condizem com a sua importância no conjunto urbano, o que acaba gerando ainda mais desequilíbrios socioespaciais.

Os dinâmicos deslocamentos pendulares atuam de forma diferenciada em um ambiente metropolitano, sobretudo, por causa da acentuada atração dos polarizadores centros urbanos e de uma forte demanda de mão de obra utilizada por diversos setores de atividades que ultrapassam os limites da cidade ou do aglomerado urbano. Assim, para o presente projeto de pesquisa optou-se pela RMG como recorte espacial de investigação pela relevância econômica, política e social desta região e pela evidente mobilidade pendular verificada nos municípios que a compõe. 
A RMG compreende um ambiente com forte participação na economia goiana, contribuindo, no ano de 2010, com mais de 37\% do Produto Interno Bruto (PIB) do estado (IMB, 2011). Além disso, a região metropolitana apresenta relevantes funcionalidades por abrigar a capital de Goiás, o que reitera sua concentração de serviços e comércio. Do ponto de vista demográfico seus vinte municípios continham $36,19 \%$ da população do estado de Goiás, dos quais 21,68\% concentravam-se em Goiânia (IBGE, 2011).

Para melhor compreensão desses deslocamentos populacionais na RMG, a presente pesquisa utilizou como recorte temporal o ano de 2010, período em que o IBGE realizou o último censo demográfico que contém informações sobre mobilidade urbana, que poderão auxiliar no entendimento dos deslocamentos pendulares e evidenciar características particulares da RMG. O objetivo geral do presente trabalho, nesse sentido, foi compreender o processo de mobilidade pendular no ano de 2010 na RMG a partir da relação entre deslocamento pendular e dinâmica socioeconômica.

Para alcançar os objetivos propostos, inicialmente, foi realizada uma pesquisa e leitura bibliográfica. Incorpora-se neste levantamento a revisão bibliográfica em livros, teses, dissertações e artigos. Concomitantemente à revisão bibliográfica, foi executada uma pesquisa documental com levantamento de dados e informações de fonte secundária junto às seguintes instituições e órgãos: censos demográficos e de deslocamento do IBGE, Secretaria do Estado de Gestão e Planejamento (SEGPLAN), IMB, Atlas de Desenvolvimento Humano no Brasil, dentre outros. E por fim houve a confecção de mapa, tabelas e gráficos que proporcionaram uma melhor visualização e assimilação da mobilidade pendular na RMG.

O trabalho está estruturado em três partes. Primeiramente abordamos a conceituação sobre a mobilidade pendular, evidenciando suas características e ligações com as regiões metropolitanas. Posteriormente narramos o modo como ocorreu o processo de urbanização no Brasil e como os debates sobre deslocamentos pendulares estiveram interligados à formação das regiões metropolitanas. Por fim, expomos sucintamente o histórico da RMG, o modo como Goiânia se mostra como um articulador centro de polarização, dados e reflexões a respeito dos movimentos pendulares e sua associação com algumas funções públicas.

\section{Caracterização da mobilidade pendular}

Desde os primórdios das primeiras civilizações, a mobilidade é tida como característica básica da população em todos os estágios evolutivos. Incontestavelmente, o crescimento econômico e tecnológico está em constante ascensão, consequentemente, há a expansão dos meios de transportes e comunicação, acarretando nas constantes e crescentes mobilidades.

Para começar a discussão a respeito da mobilidade pendular é necessário que primeiramente haja um entendimento de todos os aspectos e conceitos envolvidos quando utilizamos a expressão mobilidade. Este conceito tem aparecido nas análises 
geográficas, sobretudo, com uma preocupação de interpretar a espacialização dos fenômenos.

Segundo Lévy (2000, p.1), "pode-se definir a mobilidade como a relação social ligada à mudança de lugar, isto é, como o conjunto de modalidades pelas quais os membros de uma sociedade tratam a possibilidade de eles próprios ou outros ocuparem sucessivamente vários lugares". Com este conceito, percebe-se que a mobilidade é definida como uma relação social interligada com as mudanças de lugares. Trata-se do ir e vir dos indivíduos e suas chances de se apropriarem dos lugares. De acordo com o referido autor, a urbanização carrega consigo o crescimento das mobilidades intraurbanas, logo, apreendemos que a mobilidade está em plena expansão.

É comum estudos sobre os movimentos de mudanças de lugares utilizarem o termo migração. Durante um período considerou-se uma distinção entre migrações periódicas e definitivas, destacando-se às migrações para o trabalho e/ou estudo, chamadas de migrações pendulares (BRUNET, FERRAS e THÉRY, 1993).

O conceito de mobilidade pendular na Geografia é antigo, aparecendo nas análises de Beaujeu-Garnier (1967) como migração cotidiana, migração pendular, movimentos diários ou movimentos de vaivém. "Devido à sua feição característica - um movimento de vaivém semelhante à oscilação de um pêndulo - podem, talvez, ser denominadas "migrações oscilatórias"' (1967, p. 284). Esta autora também utiliza o termo em inglês "commuting" que significa o ato de viajar diariamente entre a casa e o trabalho, realizando movimentos pendulares.

O movimento pendular é caracterizado pelo deslocamento diário das pessoas de suas residências para os locais de destino, seja para o trabalho, estudo, tratamentos de saúde etc. Logo, no âmbito do texto utilizou-se o termo deslocamento ou movimento pendular, pois implica numa dinâmica de deslocamento cotidiano, diferindo-se das migrações por não possuir fixação definitiva em outro lugar.

Os deslocamentos entre o município de residência e outros municípios possuem finalidades específicas nos movimentos pendulares. No Censo Demográfico de 2000 do Instituto Brasileiro de Geografia e Estatística (IBGE), por exemplo, foram consideradas as condições de trabalho e estudo. A mobilidade irá expressar o modo e as razões que levam as pessoas a se deslocarem nas cidades. Logo, as pessoas estão em contínuo movimento e os motivos para os usos do sistema de circulação são os mais diversos. Porém, a maioria da população se desloca com dificuldades, sobretudo as que vivem em áreas segregadas.

Vasconcellos (2011) elucida que os fatores principais que influenciam na mobilidade das pessoas são a renda, o gênero, a idade, a ocupação e o nível educacional. Assim, estes fatores irão influenciar a movimentação. As pessoas que possuem baixa renda ou que não possuem uma função bem qualificada no mercado de trabalho, por exemplo, irá ter mais dificuldades com os deslocamentos.

As distâncias tornam-se essenciais quando tocamos no assunto mobilidade. Logo, Lévy (2000) descreve que as distâncias-custo, distâncias-tempo e todas as distâncias que são dependentes das relações sociais ou do psíquico, não devem ser 
inferiorizadas. Elas são, portanto, essenciais perante a dinâmica da mobilidade. As pessoas que estão constantemente se deslocando percebem o tempo de uma maneira bastante particular e específica, porque o tempo não se dissocia de seu conteúdo. Assim, o tempo será fator crucial nas mobilidades.

É necessário salientar que as inúmeras viagens diárias realizadas na cidade acarretam em um desperdício de tempo. Com inúmeros minutos perdidos em função do deslocamento, ocorre o aparecimento dos sintomas negativos sobre a saúde e integridade física.

Os movimentos pendulares contribuem para uma integração entre as áreas e acabam agregando numa única área meios de consumo, serviços públicos, comércio, indústria, oportunidades de emprego, fluxos de mercadorias, pessoas, dentre outros.

Segundo George (1983), na maior parte dos centros urbanos tornou-se difícil encontrar uma moradia que se ajuste ao orçamento familiar. Logo, as habitações mais econômicas se localizam nas áreas periféricas desses centros. Habitualmente, algumas pessoas irão ultrapassar os limites administrativos dos municípios para desempenhar suas atividades profissionais ou estudantis. Por conseguinte, o referido autor evidencia que o deslocamento diário da população é um aspecto da mobilidade urbana e

esta possui como causa a crescente separação geográfica entre os diversos lugares de atividade e os lugares de residência nas grandes cidades modernas. Resulta de uma simultaneidade de movimentos de mesma natureza e da distribuição horária contígua, mas de componentes geográficos diferentes (GEORGE, 1983, p. 190).

Os movimentos populacionais, acrescenta George (1983), são centrípetos de manhã e centrífugos à noite, sendo ritmados pelos horários de trabalho e/ou estudos. A mão de obra utilizada por diversos setores de atividades é requisitada além dos limites da cidade ou do aglomerado urbano. Estes limites são ultrapassados para atingir as cidades que fazem parte, juntamente com o centro principal, de uma conurbação, ou para sugar o mercado rural de mão de obra (GEORGE, 1983). "Portanto, não se trata mais de um fenômeno próprio da vida da cidade, mas de um fenômeno de irradiação exterior da cidade que deve ser estudado em conjunto com outras formas de irradiação urbana" (1983, p.192).

A urbanização está presente no cotidiano de muitas pessoas e conforme ocorre o seu crescimento as populações tendem a viver nas aglomerações de maior porte, como em regiões metropolitanas, capitais regionais ou cidades de porte médio. Por conseguinte, Taschner e Bógus (1986) destacam que as regiões metropolitanas surgem como "ilhas" de concentração populacional. Porém, não oferecendo as mesmas condições e equipamentos essenciais à reprodução da vida para toda população. Logo, ocorrerá instantaneamente o aumento da distância entre as moradias das populações dos polarizadores centros urbano. 
A mobilidade pendular, nesse sentido, não demonstra apenas a exacerbada distância percorrida entre a moradia e o trabalho, mas, sobretudo destaca à forte segregação espacial da população pendular.

\section{A mobilidade pendular no Brasil e em Goiás}

O processo de urbanização tem sido recorrente ao longo da história do Brasil. Os fenômenos das diversas migrações e deslocamentos contribuíram para as profundas transformações estruturais e sociais em todo o território nacional.

Entre os anos de 1930 e 1970 os deslocamentos populacionais brasileiros estiveram interligados coma vasta transferência da população do meio rural para o urbano. Baeninger (2000) destaca que nesse período houve uma intensa metropolização, uma pujante concentração urbana e migrações com destinos às fronteiras agrícolas. Porém, em meados de 1970 já era perceptível o desgaste dos deslocamentos para as fronteiras agrícolas e iniciavam-se os deslocamentos do tipo urbano-urbano, marcando a concentração da população em cidades maiores.

Inicialmente os centros urbanos do Sudeste foram o que receberam o maior saldo migratório do país. A Região Metropolitana de São Paulo se mantém até hoje como o centro que mais recebe migrantes em números absolutos bem como de deslocamentos pendulares em sua área metropolitana. O Sudeste se mantém na década de 1990 na centralidade migratória nacional e as migrações de longas distâncias são diminuídas. A década de 1980 e 1990 é marcada pela queda no crescimento da população brasileira e pela manifestação de novas formas de distribuição espacial (BAENINGER, 2000).

De acordo com estudos de resultados da amostra sobre migração e deslocamento do IBGE (2000), foi no ano de 1970 que o censo demográfico iniciou estudos sobre a questão de deslocamento, caracterizado pela pergunta "município onde trabalha ou estuda". Porém, esta informação não está presente nos volumes de resultados, mesmo tendo sido objeto de tabulações. Já no censo demográfico de 1980, foi também inserido a pergunta o "município em que trabalha ou estuda". Em 1991 estas perguntas não foram incluídas nos questionários e este desaparecimento fez falta nas análises do mercado de trabalho e foi solicitada sua inclusão no próximo censo. Logo, no censo demográfico de 2000 foram introduzidas definitivamente as investigações sobre deslocamento. No ano de 2010 foi instaurada a separação em dois blocos distintos: um para trabalho e outro para estudo.

Segundo Jardim e Ervatti (2006), os debates à cerca das mobilidades pendulares inicialmente foram associados aos ampliamentos das metrópoles e sua área de influência interligada à centralidade do mercado de trabalho. Embora o trabalho e o estudo ocupem posição central em alguns estudos e censos demográficos sobre deslocamentos diários, a mobilidade pendular vai muito além, abarcando diferentes ações no cotidiano dos indivíduos. Infelizmente o levantamento censitário do IBGE possui limitações em seus questionários, dando ênfase apenas para os deslocamentos para trabalho ou estudo, impossibilitando desta forma uma investigação mais aprofundada às questões ligadas aos 
deslocamentos para o lazer, saúde, acesso aos exercícios das crenças religiosas, consumo de bens e serviços, dentre outros.

O censo demográfico de 2000 do IBGE constatou que de um total de 169.872.856 pessoas entrevistadas na semana de referência, destas 6.655.162 trabalhavam ou estudavam fora do município de residência, perfazendo aproximadamente um total de $4 \%$ da população total do Brasil. Percebe-se através dos dados que os deslocamentos para estudar ou trabalhar fora do município é um fenômeno, sobretudo, urbano, pois $91,4 \%$ (6.085.729 pessoas) dos deslocamentos possuem origem urbana e estão distribuídos nas grandes áreas urbanas e vizinhanças imediatas.

De acordo com o IBGE (2000), os deslocamentos para fora do município de residência possuem maior concentração na Região Sudeste, com 3.926.029 pessoas se movimentando diariamente, ou seja, aproximadamente $59 \%$ do total de deslocamentos nacional e posteriormente a Região Nordeste com 1.188 .138 pessoas se deslocando

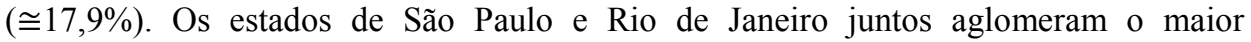
quantitativo populacional de deslocamentos do Brasil, possuindo um total de 3.052.220, ou seja, $45,8 \%$ da população total que se desloca. Já a Região Norte possui o mais baixo percentual de deslocamento, 170.277 pessoas se deslocando $(2,5 \%)$.

A Região Centro-Oeste possuía 238.856 pessoas se deslocando para trabalho ou estudo para outros municípios, destacando-se o estado de Goiás com 165.829, ou seja, $69,4 \%$ dos deslocamentos realizados na Região Centro-Oeste estão presentes no estado de Goiás. Já o estado do Mato Grosso do Sul é o que possuía o menor índice de deslocamento da região, contando com 23.221 pessoas se movimentando pendularmente, perfazendo um total de $9,7 \%$ do total de deslocamentos do Centro-Oeste (IBGE, 2000). Já no Censo de 2010 a Região Centro-Oeste passou a contar com 696.069 deslocamentos de pessoas com 10 anos ou mais de idade para exercício do trabalho em outros municípios e os deslocamentos para escola ou creche com o quantitativo de 311.580, desta forma verifica-se o crescente aumento dos movimentos pendulares.

O estado de Goiás em 2010 apresentou um total de 450.114 pessoas com 10 anos ou mais de idade se deslocando para o trabalho e 146.853 pessoas com 10 anos ou mais de idade se deslocando para escola. Desta maneira, Goiás conta com um total de 596.967 deslocamentos. Ao longo dos 10 anos, houve um crescimento de aproximadamente $260 \%$ nos movimentos pendulares (IBGE).

\section{A mobilidade pendular na Região Metropolitana de Goiânia}

O termo "região metropolitana" no âmbito jurídico surgiu pela primeira vez na legislação brasileira na Constituição de 1967, sob a forma do artigo número $157 . \mathrm{Na}$ mesma, definiu-se que a União, através de lei complementar, poderia definir regiões metropolitanas, constituídas por municípios que integravam como unidade socioeconômica que necessitavam da integração de seus serviços comuns.

É possível afirmar que a Constituição de 1967 é de caráter centralizador. Conforme Arrais (2012), “o arranjo metropolitano brasileiro é tributário de uma cultura político-institucional cuja ambição era reconhecer um conjunto de regiões para fins de 
políticas territoriais". O mesmo padrão estendeu-se até a Constituição de 1973, porém, esta criou de fato, através da Lei Complementar $\mathrm{n}^{0} 14$, as primeiras regiões metropolitanas brasileiras.

Com a promulgação da Constituição Federal de 1988 - art. $25 \S 3^{\circ}$ foi transferido aos Estados à competência para instituir regiões metropolitanas. Nesse contexto, através da Lei Complementar $\mathrm{n}^{\circ} 27$ de 30 de dezembro de 1999, foi criada a RMG, autoriza a instituir o Conselho de Desenvolvimento da Região Metropolitana de Goiânia (CODEMETRO), e a constituir o Fundo de Desenvolvimento Metropolitano.

Com a Lei Complementar $n^{\circ} 78$ de 25 de março de 2010, que altera a Lei Complementar $n^{\circ}$ 27/1999, a RMG passa a ser constituída por 20 Municípios: Goiânia, Abadia de Goiás, Aparecida de Goiânia, Aragoiânia, Bela Vista de Goiás, Bonfinópolis, Brazabrantes, Caldazinha, Caturaí, Goianápolis, Goianira, Guapó, Hidrolândia, Inhumas, Nerópolis, Nova Veneza, Santo Antônio de Goiás, Senador Canedo, Terezópolis de Goiás e Trindade distribuídos em uma faixa territorial de $3,980 \mathrm{~km}^{2}$.

Assim, a RMG está sob direta influência de Goiânia, o município polarizador. Segundo Arrais (2006), a centralidade de Goiânia ocorre porque a mesma concentra maior densidade de serviços públicos, escolas, comércio, hospitais, indústrias, oportunidades de empregos e lazer etc. Os municípios de residência dos indivíduos que se deslocam acabam possuindo condições inferiores, principalmente, de infraestrutura, oferta de empregos e serviços públicos.

É importante salientar a forma com que os deslocamentos ocorrem na RMG, porque a condição de centralidade ocorreu simultaneamente a constituição dos meios de deslocamento (malha viária intra-metropolitana).

Desse modo, há uma relação entre centralização (Goiânia), dispersão da população de baixa renda para os municípios periféricos e, ao mesmo tempo, existência de uma oferta de transporte precário do ponto de vista da qualidade, mas lucrativa para os grupos que monopolizam sua oferta. Ao considerar Goiânia como um território de destino, afirmamos que aqueles que se deslocam estabelecem relações funcionalmente desiguais com a cidade, especialmente para o trabalho. (ARRAIS, 2006, p.11)

De acordo com dados do Atlas de Desenvolvimento Humano no Brasil (2015), a RMG, em 2010, possuía 2.173.141 habitantes. A população cresceu entre 2000 e 2010 a uma taxa média anual de $2,23 \%$, superior à taxa nacional que foi de $1,17 \%$ no mesmo período. Contudo, assinalam-se variações nas taxas de crescimento geométrico (TCG) da população entre os municípios, como pode ser observado na tabela 01 , como exemplos, Goianira (6,17\%) e Senador Canedo (4,75\%). Já do ano de 2012 para 2013, Senador Canedo (6,55\%) e Santo Antônio de Goiás $(6,23 \%)$ apresentaram os maiores TCGs, Aparecida de Goiânia $(5,57 \%)$ e Goianápolis $(2,82 \%)$ e Guapó $(2,88 \%)$ os menores índices - enquanto Goiânia entre 2000 e 2010 apresentou uma TCG de 1,77\% e entre 2012 e 2013 , de $4,48 \%$. 
Tabela 01. Taxa de Crescimento Geográfico Populacional.

\begin{tabular}{|c|c|c|}
\hline Municípios & $\begin{array}{c}\text { TCG - Entre } 2000 \text { e } 2010 \\
(\%)\end{array}$ & $\begin{array}{c}\text { TCG - Entre } 2012 \text { e } 2013 \\
(\%)\end{array}$ \\
\hline Abadia de Goiás & 3,30 & 5,63 \\
\hline Aparecida de Goiânia & 3,08 & 5,57 \\
\hline Aragoiânia & 2,68 & 5,19 \\
\hline Bela Vista & 2,48 & 5,05 \\
\hline Bonfinópolis & 0,56 & 5,76 \\
\hline Brazabrantes & $-1,50$ & 4,30 \\
\hline Caldazinha & $-0,79$ & 4,24 \\
\hline Caturaí & $-0,02$ & 3,59 \\
\hline Goianápolis & 0,02 & 2,82 \\
\hline Goiânia & 1,77 & 4,48 \\
\hline Goianira & 6,17 & 5,88 \\
\hline Guapó & $-0,08$ & 2,88 \\
\hline Hidrolândia & 2,89 & 5,35 \\
\hline Inhumas & $-0,94$ & 3,75 \\
\hline Nerópolis & 2,68 & 5,2 \\
\hline Nova Veneza & 2,4 & 4,98 \\
\hline Santo Antônio de Goiás & 4,24 & 6,23 \\
\hline Senador Canedo & 4,75 & 6,55 \\
\hline Terezópolis de Goiás & $-2,52$ & 5,11 \\
\hline Trindade & 2,52 & 5,08 \\
\hline RMG & 2,14 & 4,85 \\
\hline
\end{tabular}

Fonte: IBGE (2000, 2010, 2012 e 2013); Elaboração: NUNES, L. C.

Dessa maneira, observa-se a presença do processo de involução metropolitana, caracterizado por Santos e Silveira (2006), que é identificado por meio do crescimento populacional em maior proporção nos municípios periféricos e conurbados, de acordo com os mesmos autores, levando a propagação de lugares para exercício dos capitais hegemônicos, permitindo a fragmentação do território e uma nova divisão social e territorial do trabalho.

A RMG detém 2.130.074 habitantes na área urbana, perfazendo 98,02\% da população total. Já a área rural possui apenas $1,98 \%$ dessa população. A RMG exibe uma demografia que apresenta alta representatividade em relação ao estado de Goiás. No ano de 2010 , por exemplo, $36,19 \%$ da população do estado de Goiás se concentravam na RMG. Goiânia e Aparecida de Goiânia representaram a maior parte de contingente populacional, com $59,91 \%$ e $20,96 \%$, respectivamente, dos 2.173 .141 habitantes da RMG. Estes números expõem que existe uma concentração populacional em Goiânia e também a baixa participação demográfica de municípios incluídos na RMG, a exemplo de Brazabrantes e Caturaí, com populações inferiores a 5.000 habitantes (IBGE, 2010).

Kayser (1980) atesta que não há uma verdadeira região sem centro. Desta maneira, a organização concreta do fenômeno de regionalização deve se basear sobre um eixo, o pólo ou núcleo, os mesmos se baseariam em atividades de população empregada em comércio, bancos, companhias de seguros, hotéis, etc. 
Tabela 02. Indicadores de centralidade na Região Metropolitana de Goiânia.

\begin{tabular}{|c|c|c|c|c|}
\hline Municípios & $\begin{array}{l}\text { Agências Bancárias - } \\
2012\end{array}$ & $\begin{array}{c}\text { Casas Lotéricas - } \\
2014\end{array}$ & $\begin{array}{l}\text { Hospitais - } \\
\quad 2014\end{array}$ & $\begin{array}{c}\text { Estabelecimentos } \\
\text { de ensino - } 2013\end{array}$ \\
\hline Abadia de Goiás & 0 & 1 & 0 & 8 \\
\hline Aparecida de Goiânia & 25 & 17 & 15 & 203 \\
\hline Aragoiânia & 0 & 1 & 1 & 7 \\
\hline Bela Vista de Goiás & 3 & 1 & 2 & 17 \\
\hline Bonfinópolis & 0 & 1 & 1 & 6 \\
\hline Brazabrantes & 0 & 1 & 0 & 5 \\
\hline Caldazinha & 1 & 1 & 0 & 3 \\
\hline Caturaí & 0 & 1 & 1 & 2 \\
\hline Goianápolis & 1 & 1 & 1 & 9 \\
\hline Goiânia & 215 & 117 & 129 & 742 \\
\hline Goianira & 2 & 1 & 2 & 18 \\
\hline Guapó & 3 & 1 & 1 & 12 \\
\hline Hidrolândia & 2 & 1 & 1 & 22 \\
\hline Inhumas & 5 & 4 & 6 & 47 \\
\hline Nerópolis & 4 & 1 & 1 & 15 \\
\hline Nova Veneza & 1 & 1 & 1 & 5 \\
\hline $\begin{array}{l}\text { Santo de Antônio de } \\
\text { Goiás }\end{array}$ & 0 & 1 & 1 & 4 \\
\hline Senador Canedo & 5 & 4 & 4 & 61 \\
\hline Terezópolis de Goiás & 0 & 1 & 0 & 7 \\
\hline Trindade & 4 & 7 & 5 & 57 \\
\hline Total RMG & 271 & 164 & 172 & 1250 \\
\hline
\end{tabular}

Fonte: Associação de Bancos de Goiás, Maranhão e Tocantins, 2012; Cadastro Nacional de Estabelecimentos de Saúde - Secretaria de Atenção à Saúde do Ministério da Saúde, 2014; Caixa Econômica Federal, 2014 e Instituto Mauro Borges - Banco de Dados Estatísticos de Goiás, 2013.

Elaboração: NUNES, L. C.

A condição de centralidade exercida por Goiânia associa-se a concentração de meios de consumo, serviços públicos, comércio, indústria, oportunidades de emprego etc. Os dados dispostos na tabela 02 confirmam os argumentos sobre a centralidade desempenhada por Goiânia. O município de Goiânia chegou a possuir 79,33\% (2012) das agências bancárias da região, 75\% dos hospitais (2014) e 59,36\% (2013) de estabelecimentos de ensino. Diante disso, o trabalho é um dos motivos mais frequentes da mobilidade pendular, acarretando às maiores possibilidades de rendimento e empregabilidade. A aglomeração econômica praticada por Goiânia possibilitou a 
concentração de serviços públicos e privados, por conseguinte, somado ao fato de o pólo ser a capital do estado, fez crescer a oferta de emprego (ARRAIS, 2006).

Os deslocamentos na RMG entre 2000 e 2010 cresceram em média 12\% ao ano, perfazendo um total de 260.882 pessoas se deslocando no ano de 2010. Diferentemente do ano de 2000, em 2010 o censo demográfico tabulou dados de deslocamentos para trabalho e para escola ou creche, separadamente. Dessa forma, 190.792 pessoas deslocam-se para trabalhar em outro município e 70.090 pessoas para frequentar escola ou creche (IBGE, 2010), como pode ser visualizada na figura 01.

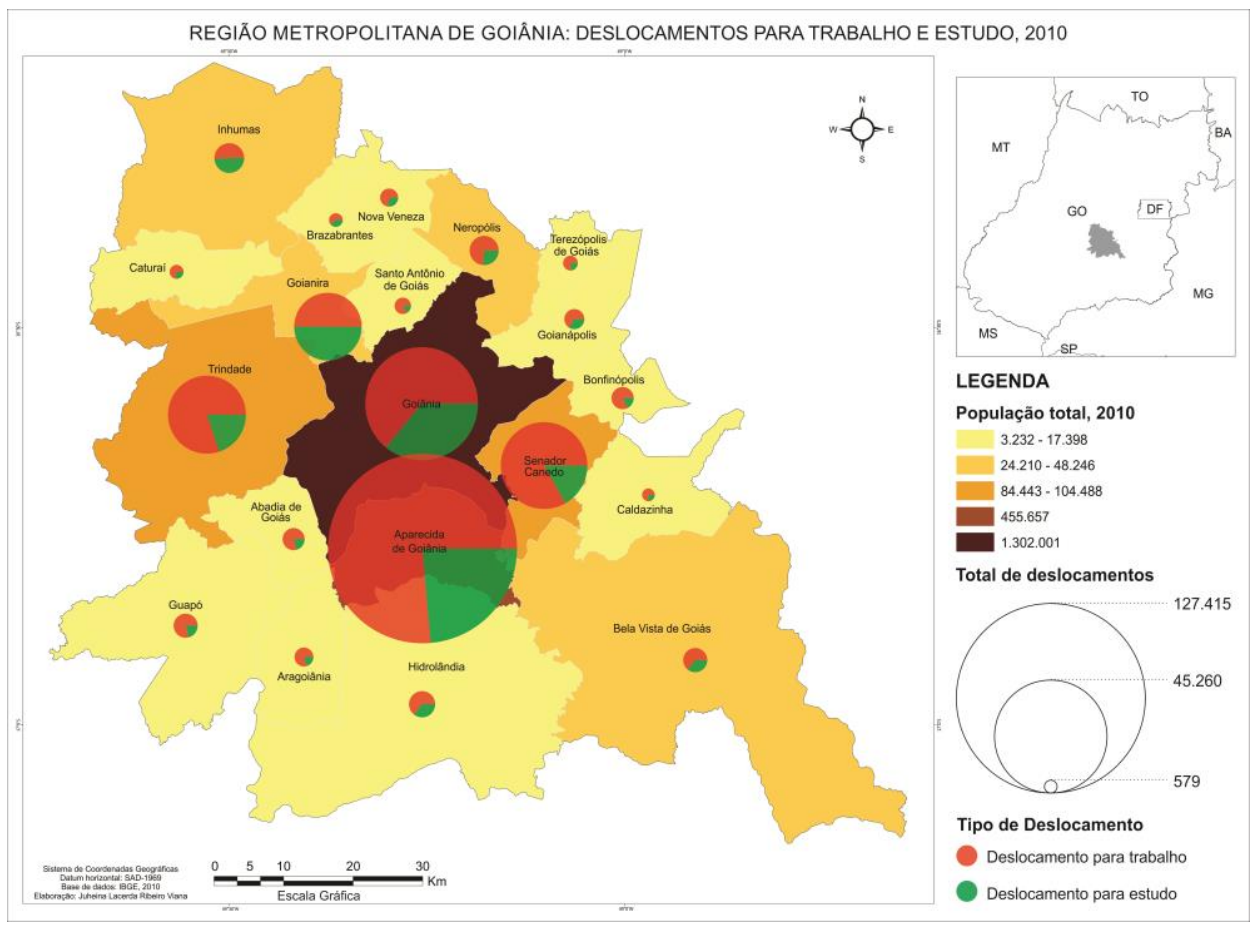

Figura 01: Mapa de deslocamentos para trabalho e estudo na RMG.

Fonte: IBGE (2010). Elaboração: Juheina Lacerda Ribeiro Viana.

Aparecida de Goiânia, Goiânia, Senador Canedo e Trindade foram os municípios com maiores números de deslocamentos para trabalho: 97.344, 29.007, 22.274, 17.297, respectivamente. Assim posto, Aparecida de Goiânia representa $51 \%$ do total de deslocamentos e Senador Canedo e Trindade somados constituem 20,74\% do total dos movimentos pendulares em função do trabalho. Os municípios que possuem maiores deslocamentos estão entre aqueles com maiores TCGs, a exemplo de Senador Canedo, Aparecida de Goiânia e Goianira (IBGE, 2010).

Arrais (2006) retrata que essa característica de maior crescimento dos municípios periféricos em relação ao pólo ocorre devido às ligações estabelecidas entre 
as pessoas que moravam e trabalhavam em Goiânia e foram morar na periferia metropolitana, o que induziu a manutenção dos vínculos de dependência com o pólo. Os indivíduos usualmente, mesmo após se mudarem de Goiânia, continuam acessando os territórios do pólo, especialmente para trabalho e estudo.

Utilizamos os dados sobre migração pendular e crescimento demográfico para argumentar que o deslocamento para o pólo relaciona-se com a origem das pessoas e com os vínculos estabelecidos anteriormente com Goiânia (seja para estudo, trabalho ou mesmo relações familiares). Nesse sentido, a relação que essa miríade de indivíduos mantém diariamente com Goiânia se dá a partir do acionamento de vários territórios. O próprio deslocar- se, a locomoção, pode ser considerada uma espécie de território complementar que permite acionar outros territórios na RMG, especialmente Goiânia (ARRAIS, 2006, p. 99).

Os municípios com os menores índices de deslocamento para o trabalho foram Caturaí (516 pessoas), Caldazinha (445 pessoas) e Brazabrantes (403 pessoas), municípios que obtiveram índices negativos de TCGs entre 2000 e 2010. Caturaí chegou a apresentar $-0,02 \%$ de taxa. Dessa maneira, apreende-se que os baixos índices de crescimento populacional possuem relação direta com os pequenos números de deslocamentos. Municípios, como Brazabrantes, possuem uma relação diferenciada com o pólo, por possuir um menor nível de integração com a dinâmica da região (IBGE, 2010).

Segundo IMB (2010), Goiânia é o município com maior concentração de número de empregos, 558.901, agropecuária (2.783), indústria (57.240), construção civil (40.965), comércio (103.974) e demais serviços (353. 939). Essa aglomeração reafirma a condição de município polarizador, uma vez que os indivíduos irão encontrar em Goiânia um número maior de oportunidades de emprego.

Os índices de deslocamentos para escola ou creche foram altos nos municípios de Aparecida de Goiânia (30.071 estudantes), Goiânia (16.253), Goianira (8.116), Senador Canedo (4.489) e Trindade (4.281). Coincidentemente, esses municípios possuem os maiores números de escolas, alunos matriculados e as menores taxas de analfabetismo da RMG, conforme se pode observar na Tabela 03. Goiânia possui a menor taxa de analfabetismo (3,15\%), os maiores números de escolas (744) e alunos matriculados (290.378), assumindo a liderança em quase todos os indicadores educacionais.

Alguns municípios possuem elevados índices de analfabetismo (acima de 10\%), dentre os quais estão Goianápolis (14,86\%), Terezópolis de Goiás $(11,61 \%)$ e Caturaí $(11,45 \%)$. Consequentemente, esses municípios possuem um baixo número de escolas e de alunos matriculados e também com número reduzido de deslocamentos para estudo. 
Tabela 03. Número de escolas, alunos matriculados e taxa de analfabetismo

\begin{tabular}{|c|c|c|c|}
\hline Municípios & $N^{0}$ de escolas -2010 & $\begin{array}{c}\text { Alunos } \\
\text { Matriculados - } \\
\mathbf{2 0 1 0}\end{array}$ & $\begin{array}{c}\text { Taxa de } \\
\text { analfabetis mo da } \\
\text { população de } 10 \\
\text { anos ou mais de } \\
\text { idade }(\%) \text { - } 2010\end{array}$ \\
\hline Abadia de Goiás & 8 & 1.914 & 7,03 \\
\hline Aparecida de Goiânia & 190 & 103.685 & 4,96 \\
\hline Aragoiânia & 7 & 2.201 & 9,4 \\
\hline Bela Vista de Goiás & 17 & 5.304 & 8,65 \\
\hline Bonfinópolis & 5 & 2.048 & 9,63 \\
\hline Brazabrantes & 5 & 696 & 9,99 \\
\hline Caldazinha & 3 & 763 & 9,74 \\
\hline Caturaí & 2 & 1.025 & 11,45 \\
\hline Goianápolis & 8 & 2.778 & 14,86 \\
\hline Goiânia & 744 & 290.378 & 3,15 \\
\hline Goianira & 16 & 8.141 & 7,64 \\
\hline Guapó & 12 & 3.283 & 9,99 \\
\hline Hidrolândia & 22 & 4.313 & 6,51 \\
\hline Inhumas & 49 & 11.771 & 9,31 \\
\hline Nerópolis & 15 & 5.986 & 7,81 \\
\hline Nova Veneza & 6 & 1.748 & 8,01 \\
\hline Santo Antônio de Goiás & 4 & 1.199 & 7,86 \\
\hline Senador Canedo & 60 & 22.496 & 6,03 \\
\hline Terezópolis de Goiás & 8 & 1.795 & 11,61 \\
\hline Trindade & 62 & 24.178 & 7,59 \\
\hline Total da RMG & 1.243 & 495.702 & 4,43 \\
\hline
\end{tabular}

Fonte: Instituto Mauro Borges de Estatísticas e Estudos Socioeconômicos (2010); Elaboração: Larissa Camilo Nunes

A mobilidade pendular reflete o nível de renda e as condições de moradia dos indivíduos (LÉVY, 2000). A figura 02 mostra dados sobre a renda per capita em reais no ano de 2000 e 2010. Goiânia se prova mais uma vez como município centralizador, possuindo uma renda per capita de $1.348,55 \mathrm{R} \$$. É comum que muitas pessoas se movimentem a procura de melhores salários. Goianápolis, por exemplo, em 2000 apresentava uma renda per capita de apenas 273,71 R\$ e Goiânia no mesmo período $1.001,94 \mathrm{R} \$$. Ocorre, muitas vezes, uma discrepância enorme entre a renda per capita obtida na capital e a renda dos municípios periféricos, principalmente dos que não estão conurbados, como Caturaí.

A mobilidade pendular acaba demonstrando as desiguais relações sociais e econômicas entre os indivíduos, o que acarreta um maior distanciamento social e as melhores infraestruturas urbanas, ofertas de emprego, oportunidades de estudos, e demais equipamentos sociais se concentram cada vez mais distante. A renda per capita é um dos indicadores que demonstram que as condições socioeconômicas da população nos municípios que se encontram mais integrada com a dinâmica da RMG, em função da 
proximidade geográfica, do quantitativo populacional, infraestrutura, dentre outros fatores, são melhores, porém, proporcionalmente são nesses municípios, como Goiânia e Aparecida de Goiânia que se encontra um número maior de pessoas em condições paupérrimas. Indivíduos que acreditam viverem em uma região integrada, quando na realidade vivem uma falsa integração - a qual ocorre de fato no caso dos atores hegemônicos.

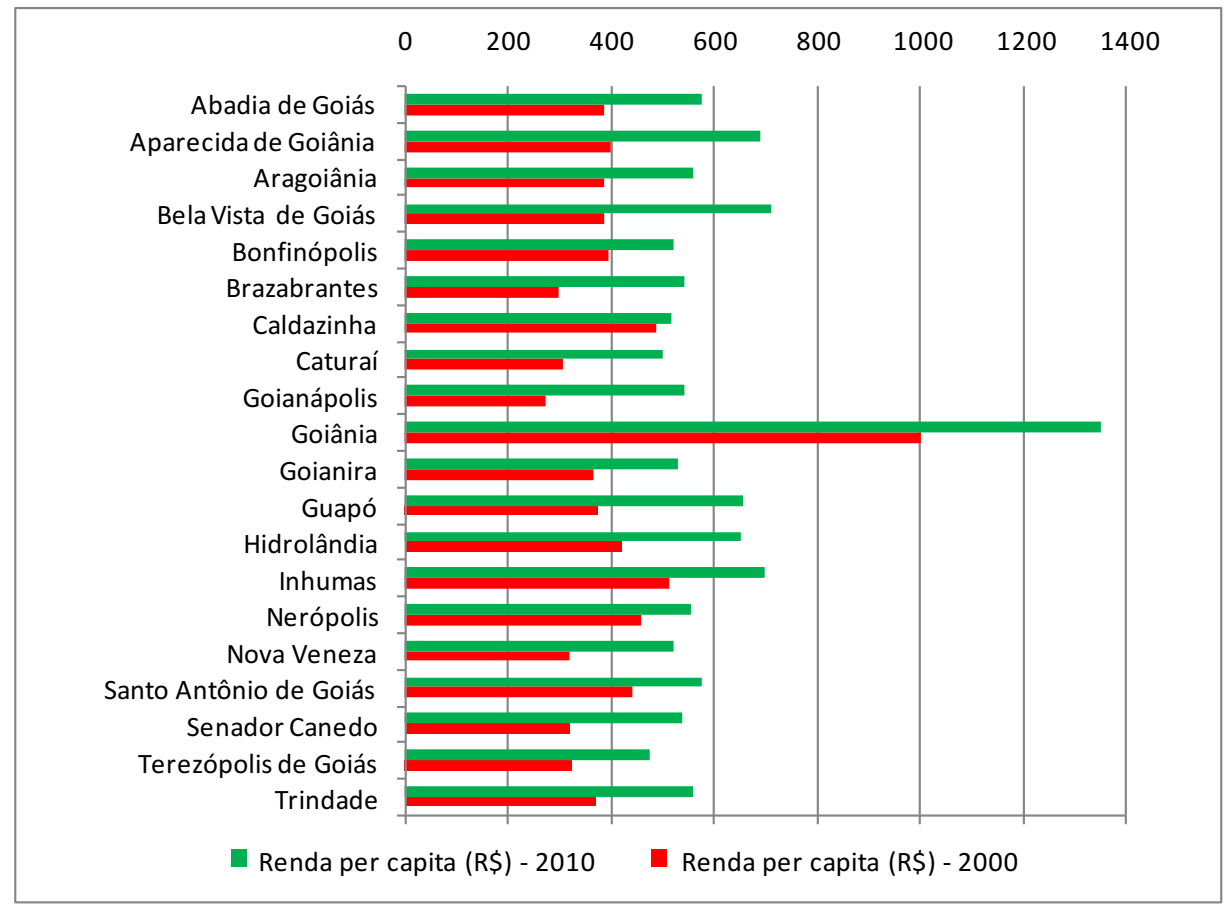

Figura 02. Renda per capita. Fonte: IMB (2010). Elaboração: NUNES, L. C.

O Saneamento básico, água tratada e o destino do lixo são funções públicas de interesse comum para a RMG. Porém, 11 municípios da RMG não possuem rede de esgoto. Esses municípios agrupam uma população de 98.840 habitantes. Todavia, mesmo nos municípios mais populosos como Goiânia, Aparecida de Goiânia e Senador Canedo, há domicílios sem rede de esgoto. Aparecida de Goiânia, por exemplo, possui apenas $19,87 \%$ da população atendida pela rede de esgoto (IMB, 2011).

A maioria dos municípios que compõem a RMG sofre com as carências infraestruturais, como a falta de iluminação, destinação do lixo urbano, precariedade na rede de esgoto, etc. De modo consequente, há o ocasionamento de impactos ambientais, que prejudicam outros recursos, como o hídrico. A presença de saneamento básico contribui para a valorização imobiliária e, principalmente, na qualidade de vida da população. Os indivíduos que não detém condições financeiras suficiente irão morar em 
regiões mais distantes, onde a infraestrutura e as funções públicas são precárias e os valores de moradia mais baixos. É notório que Goiás visou definir funções de interesse comum, mas apenas o transporte público e o sistema viário foram vistos como prioridade perante as demais funções (AZEVEDO e GUIA, 2004).

Uma função pública importante para as dinâmicas socioespaciais dos deslocamentos é às formas de ocupação e uso do solo. Como podem ser visualizados na Figura 03, alguns municípios apresentaram variações percentuais de domicílio, entre 2000 e 2010, superiores aos de Goiânia (34,75\%), como por exemplo, Goianira (96,55\%) e Santo Antônio de Goiás (71,79\%). Na RMG não houve nenhum município em que o crescimento populacional relativo fosse superior ao domiciliar. Apenas Goianápolis e Guapó, obtiveram um crescimento populacional quase a 1\%, porém, o número de domicílios apresentou percentuais maiores que $14 \%$.

Quando as terras do pólo metropolitano estão escassas e com preços elevados, é notório que há uma valorização dos estoques domiciliares urbanos e rurais dos municípios adjacentes e quanto mais distante dos centros urbanos, geralmente menores são os preços das moradias. Essa dinâmica movimenta o mercado de terras e altera as formas de uso e ocupação do solo na RMG, gerando impactos nas distâncias percorridas diariamente.

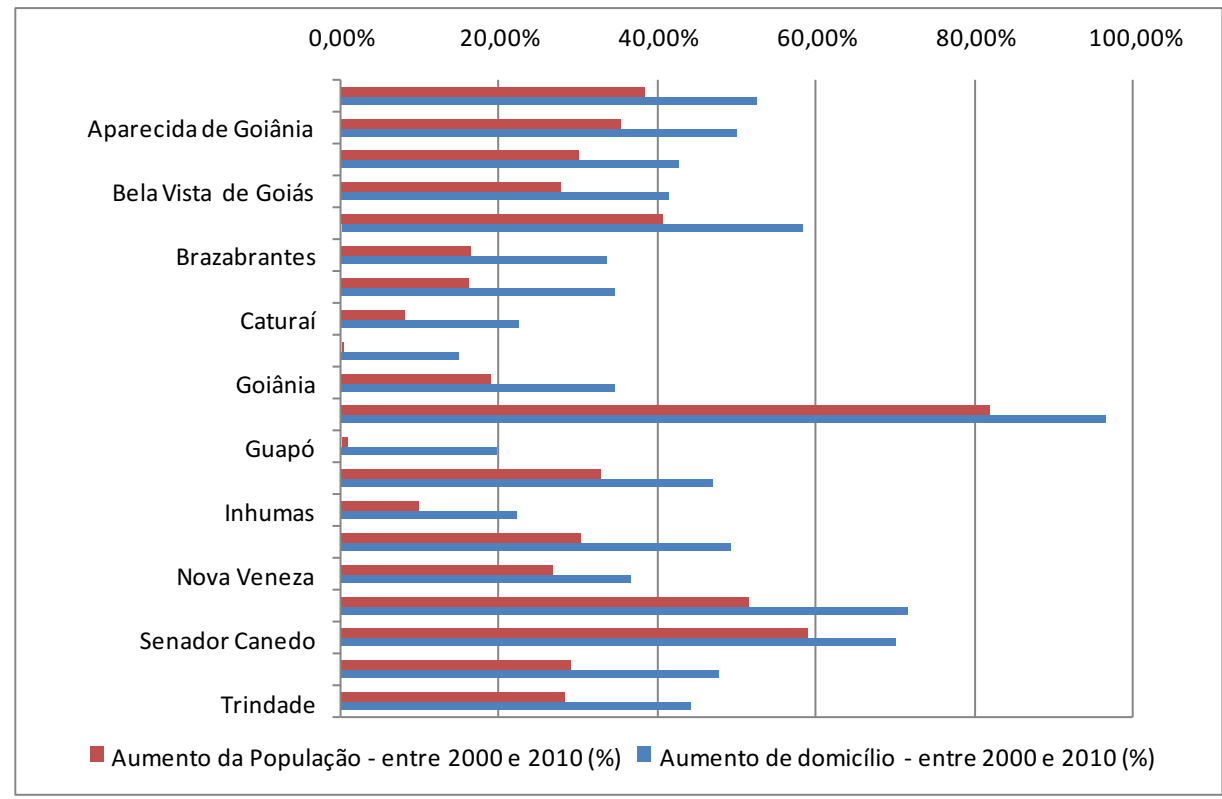

Figura 03. Aumento de domicílios e população. Fonte: IBGE (2000 e 2010); Elaboração: NUNES, L. C.

As metrópoles assumem um papel essencial não só como centros que concentram as decisões sobre os destinos da economia, como também abrigam a 
problemática da população integrada e não integrada ao processo de crescimento (MINISTÉRIO DAS CIDADES, 2008). Desse modo, os indivíduos acessam de maneira heterogênea os territórios, ocorrendo de maneira desigual a integração socioeconômica entre os diversos municípios.

Os fluxos são notadamente marcados pela utilização de transporte particular ou o coletivo. No caso da RMG, os municípios são providos com o serviço de transporte coletivo por meio da Rede Metropolitana de Transporte Coletivo de Goiânia (RMTC), atendendo, grosso modo, uma função pública de interesse comum, todavia bastante insatisfatório. Apesar de o transporte coletivo público ser um dos serviços que apresentam maior relevância para a RMG, do ponto de vista de integração dos municípios periféricos ao pólo metropolitano, o mesmo não integra alguns municípios, como Caturaí e Inhumas.

A integração é notada, por exemplo, através do transporte coletivo do Eixo Anhanguera, que interliga alguns dos principais terminais da RMG. A maioria dos terminais de integração está localizada na porção sul e, em menor proporção, noroeste de Goiânia, localização estratégica para fazer ligação com os principais municípios que atendem as demandas de mão de obra da capital. Nesse sentido, destacam-se os terminais que fazem interligação com Aparecida de Goiânia, Senador Canedo, Trindade e Goianira e também a presença de outras linhas destinadas a outros municípios, salientando a relevância do transporte coletivo como gerador de mobilidade.

A RMTC é formada por 268 linhas de ônibus, com um modelo de total integração físico-tarifária entre eles, estruturada com 19 terminais de integração (RMTC, 2016). De acordo com a Associação Nacional de Transportes Públicos (ANTP, 2011), a RMTC passou a contar com 18,5 milhões de passageiros por mês. Mas esse transporte coletivo é defícitário, tendo apresentado diversas crises nos últimos anos, principalmente pelos elevados preços tarifários, excesso de pessoas dentro dos ônibus e pelos constantes atrasos nos horários. No que concerne a esse aspecto, Harvey (1980) destaca a difícil tarefa de mensurar o impacto causado à população pela espera vinculada ao transporte coletivo.

Conforme evidencia Villaveces e Rodrigues (2009), ao se movimentarem nas regiões metropolitanas, os sujeitos estão suscetíveis há alguns fatores negativos, dentre eles estão: Aumento dos acidentes de trânsito; maiores níveis de ruído (associados a comportamentos mais agressivos); poluição do ar; degradação ambiental; a prática de hábitos sedentários associados a um elevado gasto de tempo nos deslocamentos e consequentemente, um baixo desempenho em atividades físicas; maiores níveis de estresse e surgimento de outros problemas negativos de saúde mental; e maior isolamento social, depressão e redução geral da coesão social. Os efeitos podem se manifestar de maneira branda, porém, podendo se agravar quando grande parte da população é exposta.

É importante salientar a relação entre as vias de acesso rodoviário e as distâncias em relação à Goiânia. Alguns municípios estão a mais de $30 \mathrm{~km}$ da área central da capital, como Aragoiânia (42 km) e Santo Antônio de Goiás (38 km), já outros estão em uma progressiva conurbação, especialmente os municípios de Senador Canedo 
(16 km) e Aparecida de Goiânia (21 km). Os indivíduos que se deslocam de Aparecida de Goiânia em direção ao pólo podem utilizar a BR-153, vias municipais, entre outras possibilidades. Já em relação a outros municípios como Goianápolis $(33 \mathrm{~km})$ e Aragoiânia (42 km), as possibilidades para se deslocar são mais limitadas. As vias de acesso integralizam os movimentos em direção ao pólo. Entretanto, não há uma integração entre alguns municípios da RMG. Diante do exposto, fica evidente uma mobilidade mais evidente em direção a Goiânia, município que utiliza a mão de obra periférica.

\begin{abstract}
No processo de constituição das cidades brasileiras, tradicionalmente, a população mais pobre foi empurrada para bairros distantes ou mesmo para outros municípios, aumentando, dessa forma. A distância espacial entre o local de residência e os locais de trabalho-estudo, que, no caso de RMG, pode varia de 16 $\mathrm{km}$ a $42 \mathrm{~km}$. A distância converte-se em barreira para a população mais carente, seja porque gasta mais tempo para se deslocar, com implicações na sua qualidade de vida, ou mesmo porque o preço para esse deslocamento também é maior (MINISTÉRIO DAS CIDADES, 2008, p. 114).
\end{abstract}

Os diários deslocamentos populacionais são reflexos de uma má distribuição e baixo atendimento de demandas de empregos, estabelecimentos educacionais, hospitais e demais ferramentas sociais. A lógica concentradora está presente e fortalece a segregação socioespacial das pessoas que moram mais distantes e, assim, parece não admitir que os indivíduos acessem os territórios de maneira justa.

\title{
Considerações finais
}

Conforme houve o crescimento das populações, a urbanização tornou-se presente e trouxe consigo as regiões metropolitanas. A legislação objetivava criar regiões constituídas por municípios, como forma de integrar o planejamento e a execução de funções públicas de interesse comum (BRASIL, 1967). Todavia, as regiões metropolitanas não oferecem as mesmas condições e equipamentos essenciais para a população.

Nesse sentido, os deslocamentos pendulares assumem destaque nas regiões metropolitanas brasileiras, ressaltando a centralidade de um determinado espaço, que irá se tornar pólo de atração e dispersão de fluxos de pessoas, mercadorias, serviços, informações, etc. São comuns que muitos municípios periféricos recebam menos recursos econômicos públicos, agravando os desequilíbrios socioespaciais.

Conforme há o aumento das metrópoles e suas áreas de influência, ocorrerá o aumento das distâncias percorridas entre as moradias dos indivíduos e os centros urbanos. As áreas onde residem trabalhadores que se mobilizam diariamente geralmente possuem infraestrutura baixa, menos postos de trabalho, equipamentos educacionais limitados, opções de lazer escassas, dentre outros fatores que acabam demandando a mobilidade pendular. 
Este fenômeno, portanto, é mais comum nas regiões metropolitanas em função do contingente populacional, da conurbação bem como pelos estoques de trabalho e, sobretudo, pela divisão territorial do trabalho específico da RMG.

Goiânia exerce uma intensa polarização, o que consequentemente leva ao aparecimento de diversos problemas sociais, que algumas vezes, são gerados nos municípios vizinhos. Assim sendo, é necessária a atuação efetiva dos gestores urbanos nessa heterogênea região, com ações conjuntas para que de fato ocorra uma integração socioespacial de todos os municípios da RMG.

As relações de poder estão presentes nos territórios, conforme destacou Raffestin (1993). Dessa maneira, os indivíduos acessam os territórios de maneiras distintas, estando, sobretudo a mercê dos objetivos hegemônicos. No caso da RMG, há um discurso de integralização, no entanto, isso só ocorre nas funções públicas que são interessantes à reprodução ampliada do capital.

\section{Referências}

ARRAIS, T. P. A. Acionando territórios: a mobilidade na Região Metropolitana de Goiânia e em Aparecida de Goiânia. Boletim Goiano de Geografia. Goiânia, v. 26, n.1, p.91-114, jan.- jun. 2006. Disponível em:

$<$ http://www.revistas.ufg.br/index.php/bgg/article/view/3547/15614>. Acesso em: 20 out. 2015.

ARRAIS, T. P. A. A escala de análise metropolitana em questão: considerações sobre o processo de metropolização. Revista USP. São Paulo, v. 24, n. 1, p. 4-23, 2012. Disponível em: <file://C:/Users/Larissa/Downloads/52751-66044-1-PB\%20(1).pdf>. Acesso em: 20 jan. 2016

ASSOCIAÇÃO NACIONAL DE TRANSPORTE PÚBLICO. Disponível em: < http://www.antp.org.br/>. Acesso em: 28 dez. 2015.

ATLAS DE DESENVOLVIMENTO HUMANO DO BRASIL. Disponível em: <http://www.atlasbrasil.org.br/2013/>. Acesso em: $28 \mathrm{dez} .2015$.

AZEVEDO, Sérgio de; GUIA, VR dos M. Os dilemas institucionais da gestão metropolitana no Brasil. Metrópoles: Entre a Coesão e a Fragmentação, a Cooperação e o Conflito. FASE/Ed. Fundação Perseu Abramo/Observatório das Metrópoles, 2004.

BAENINGER, Rosana. Redistribuição da população e meio ambiente: São Paulo e Centro-Oeste. Campinas: UNICAMP - Núcleo de Estudos de População, 2000.

BEAUJEU-GARNIER, Jacqueline. Geografia de População. São Paulo: Companhia Editora Nacional, 1967.

BRASIL. Constituição da República Federativa do Brasil de 1967. Publicada no Diário Oficial [da] República Federativa do Brasil, Brasília, DF, 24 jan. 1967. Disponível em: $<$ http://www.planalto.gov.br/ccivil_03/Constituicao/Constituicao67.htm\#art164>. Acesso em: 12 maio. 2015. 
BRASIL. Constituição da República Federativa do Brasil 1988. Publicada no Diário Oficial [da] República Federativa do Brasil, Brasília, DF, 5 out. 1988. Disponível em: $<$ http://www.planalto.gov.br/ccivil_03/constituicao/constituicao.htm>. Acesso em: 12 maio. 2015.

BRASIL. Lei Complementar de $N^{o} 14$, de 8 de junho de 1973. Diário Oficial [da] República Federativa do Brasil, Brasília, DF, 11 jun. 1973. Disponível em: $<$ http://www.planalto.gov.br/CCiVil_03/Leis/LCP/Lcp14.htm>. Acesso em: 12 maio. 2015.

BRUNET, Roger; FERRAS, Robert; THÉRY, Hervé. Lesmots de la Géographie. Dictionnaire critique. Montpellier - Paris: GIP Reclus et la Documentation Française, 1993.

FUNDAÇÃO INSTITUTO BRASILEIRO DE GEOGRAFIA E ESTATÍSTICA. Censo demográfico - migração e deslocamento. Rio de Janeiro, 2000. Disponível em: $<$ http://www.ibge.gov.br/home/estatistica/populacao/censo2000/migracao/censo2000_mi gracao.pdf $>$. Acesso em: 01 out. 2015.

GEORGE, P. Geografia Urbana. São Paulo: Difel, 1983.

GOIÁS. Lei Complementar n ${ }^{\circ}$ 27, de 30 de dezembro de 1999. Cria a Região Metropolitana de Goiânia, autoriza o Poder Executivo a instituir o Conselho de Desenvolvimento da Região Metropolitana de Goiânia, a Secretaria Executiva e a constituir o Fundo de Desenvolvimento Metropolitano de Goiânia e dá outras providências correlatas. Diário Oficial do Estado de Goiás de 20 de janeiro de 2000. Disponível em: $<$ http://www.gabinetecivil.go.gov.br/pagina_leis.php?id=7066>. Acesso em: 12 maio. 2015.

GOIÁS. Lei Complementar $n^{\circ} 78$, de 25 de março de 2010. Altera a Lei Complementar $\mathrm{n}^{\circ}$ 27, de 30 de dezembro de 1999, que cria a Região Metropolitana de Goiânia, autoriza o Poder Executivo a instituir o Conselho de Desenvolvimento da Região Metropolitana de Goiânia, a Secretária Executiva e a constituir o Fundo de Desenvolvimento Metropolitano de Goiânia. Diário Oficial do Estado de Goiás de 5 de abril de 2010. Disponível em: $<\mathrm{http}: / / \mathrm{www}$.gabinetecivil.go.gov.br/pagina_leis.php?id=9457>. Acesso em: 12 maio. 2015.

HARVEY, D. A justiça social e a cidade. São Paulo: Hucitec, 1980.

IBGE. Censo demográfico 2000. Rio de Janeiro: IBGE, 2003.

IBGE. Censo demográfico 2010. Rio de Janeiro: IBGE, 2011

IMB. Produto Interno Bruto a Preços Correntes - PIB. 2010. Goiânia, 2011.

JARDIM, A. P; ERVATTI, L. R. Migração pendular metropolitana no Rio de Janeiro: a condição da renda das pessoas que trabalham ou estudam fora do município de residência em 1980 e 2000. Anais... Encontro Nacional de Estudos Populacionais, 15., 2006, Caxambu-MG. p. 1-17. 
KAYSER, B. A região como objeto de estudo da geografia. In: GEORGE, P., KAYSER, B., GUGLIELMO, R. \& LACOSTE, Y. A Geografia Ativa. $5^{\text {a }}$ edição, p. 279-321. São Paulo/Rio de Janeiro: Difusão Editorial S.A., 1980.

LÉVY, J. Os novos espaços da mobilidade. RevistaGEOgraphia. Rio de Janeiro, v. 3, n. 6, p. 7-17. 2000.

MINISTÉRIO DAS CIDADES. Como andam Belém e Goiânia. Brasília, 2008.

RAFFESTIN, C. Por uma Geografia do Poder. França. São Paulo: Ática, 1993.

RMTC. Informações constitucionais. Goiânia, 2016.

SANTOS, M; SILVEIRA, M. L. O Brasil: território e sociedade no início do século XXI. 9. ed. Rio de Janeiro: Record, 2006.

TASCHNER, S. P; BÓGUS, L. M. M. Mobilidade espacial da população brasileira: aspectos e tendências. Revista Brasileira de Estudos de Populações. Campinas, v. 3, n. 2, p. 87-132, jul.- dez. 1986.

VASCONCELLOS, E. A. Transporte urbano, espaço equidade - Análise das políticas públicas. São Paulo: Annablume, 2001.

VILLAVECES A; RODRIGUES, E.M.S. Pela defesa do transporte público seguro e saudável: maior participação da saúde em uma estrutura multissetorial. Washington (DC): Organização Pan-Americana da Saúde, 2009. Disponível em: < http://www.bvsde.paho.org/texcom/cd045364/defentransp-pt.pdf $>$. Acesso em: 25 jan. 2016.

\section{Larissa Camilo Nunes}

Possui graduação em Geografia pela Universidade Federal de Goiás. Atualmente é mestranda em Geografia pelo Instituto de Estudos Socioambientais da Universidade Federal de Goiás, onde desenvolve pesquisas na área de Geografia Urbana e Demografia.

Avenida Esperança, s/n, Câmpus Samambaia. IESA/UFG. CEP: 74690-900. Goiânia (GO).

E-mail: larissacamilonunes@gmail.com

Recebido para publicação em novembro de 2016 Aprovado para publicação em maio de 2017 